OPEN ACCESS

Edited by:

Nlingisisi Dombole Babayani, University of Botswana, Botswana

Reviewed by:

Fabio Macchioni, Università di Pisa, Italy

Hüseyin Can

Ege University, Turkey

*Correspondence:

Shewit Kalayou skalayou@icipe.org

Specialty section:

This article was submitted to

Parasitology,

a section of the journal

Frontiers in Veterinary Science

Received: 30 July 2021

Accepted: 04 October 2021

Published: 02 November 2021

Citation:

Kalayou S, Okal MN, Odhiambo PO, Mathenge K, Gamba DO, Kariuki E, McOdimba F and Masiga D (2021)

Prevalence of Trypanosome Species in Cattle Near Ruma National Park, Lambwe Valley, Kenya: An Update From the Historical Focus for African Trypanosomosis.

Front. Vet. Sci. 8:750169 doi: 10.3389/fvets.2021.750169

\section{Prevalence of Trypanosome Species in Cattle Near Ruma National Park, Lambwe Valley, Kenya: An Update From the Historical Focus for African Trypanosomosis}

\author{
Shewit Kalayou ${ }^{1 *}$, Michael Nyang'anga Okal ${ }^{1}$, Peter Otieno Odhiambo ${ }^{\text {, }}$ \\ Kawira Mathenge ${ }^{1}$, Daniel Ochieng Gamba ${ }^{2}$, Edward Kariuki ${ }^{3}$, Francis McOdimba ${ }^{1,4}$ and \\ Daniel Masiga $^{1}$ \\ ${ }^{1}$ International Centre of Insect Physiology and Ecology (icipe), Nairobi, Kenya, ${ }^{2}$ Kenya Tsetse and Trypanosomiasis \\ Eradication Council (KENTTEC), Nairobi, Kenya, ${ }^{3}$ Veterinary and Capture Service Department, Kenya Wildlife Service, \\ Nairobi, Kenya, ${ }^{4}$ Department of Biological Sciences, Faculty of Science, Egerton University, Nairobi, Kenya
}

The effective control of diseases in areas shared with wildlife depends on the validity of the epidemiologic parameters that guide interventions. Epidemiologic data on animal trypanosomosis in Lambwe valley are decades old, and the recent suspected outbreaks of the disease in the valley necessitate the urgent bridging of this data gap. This cross-sectional study estimated the prevalence of bovine trypanosomosis, identified risk factors, and investigated the occurrence of species with zoonotic potential in Lambwe valley. The area is $\sim 324 \mathrm{~km}^{2}$, of which $120 \mathrm{~km}^{2}$ is the Ruma National Park. Blood was sampled from the jugular and marginal ear veins of 952 zebu cattle between December 2018 and February 2019 and tested for trypanosomes using the Buffy Coat Technique (BCT) and PCR-High-Resolution Melting (HRM) analysis of the 18S RNA locus. Risk factors for the disease were determined using logistic regression. The overall trypanosome prevalence was $11.0 \%$ by BCT [95\% confidence interval (Cl): 9.0-13.0] and $27.9 \%$ by PCR-HRM (95\% Cl: 25.1-30.8). With PCR-HRM as a reference, four species of trypanosomes were detected at prevalences of $12.7 \%$ for T. congolense savannah (95\% Cl: 10.6-14.8), 7.7\% for T. brucei brucei (Cl: 6.0-9.4), 8.7\% for T. vivax (Cl: 6.9-10.5), and $1.3 \%$ for T. theileri (Cl: $0.6-2.0)$. About $2.4 \%$ of cattle had mixed infections $(\mathrm{Cl}$ : 1.4-3.41). No human-infective trypanosomes were found. Infections clustered across villages but were not associated with animal age, sex, herd size, and distance from the park. Approximately $85 \%$ of infections occurred within $2 \mathrm{~km}$ of the park. These findings add to evidence that previous interventions eliminated human trypanosomosis but not bovine trypanosomosis. Risk-tailored intervention within $2 \mathrm{~km}$ of Ruma Park, especially in the north and south ends, coupled with stringent screening with molecular tools, could significantly reduce bovine trypanosomosis.

Keywords: bovine trypanosomosis, T. brucei subgroup, T. congolense savannah, T. vivax, wildlife-livestock interface, Lambwe valley, prevalence 


\section{INTRODUCTION}

Since time immemorial, several countries in sub-Saharan Africa have struggled with the debilitating burden of human and animal trypanosomosis. This group of diseases caused by protozoan parasites of the genus Trypanosoma and transmitted primarily by tsetse flies limits human health and livestock production in more than 32 countries of sub-Saharan Africa (1). Several interventions with varied intensity, frequency, approach, and success rates $(2,3)$ have been implemented in different regions, with significant progress in controlling the disease in humans and animals. With $<1,000$ cases of Human African Trypanosomosis (HAT) now reported in a year, the focus is on eliminating the disease by 2030 (4). On the contrary, Animal African Trypanosomomosis (AAT) is still widespread, occurring in more than 10 million $\mathrm{km}^{2}$ of land where it kills about 3 million cattle every year (1). Approximately one-quarter of Kenya is tsetse infested and endemic for AAT (5). The impact of AAT is disproportionate; persons living near wildernesses, wildlife protectorates, and other interfaces with wildlife, such as that of the Ruma National Park (RNP) in Lambwe valley, bear the brunt of the disease.

Lambwe valley epitomizes the struggle against HAT and AAT $(6,7)$. Evidence suggests that several trypanosome species circulated long before the first unnamed settler arrived in 1951 (8). However, it was the detection of the zoonotic Trypanosoma brucei rhodensiense in the valley in 1959 (9) and the consequent steep rise in cases of sleeping sickness (8) that necessitated studies aimed at characterizing the epidemiology of trypanosomes in the valley in attempts to eradicate the diseases. The major tsetse population that infests Lambwe valley, Glossina pallidipes, is resilient and has repeatedly recovered from attempts at eradication in the last half a century. Between 1968 and 1971, bushes were cleared, and residual dieldrin was applied to the valley with aerial and ground spraying (8). This was repeated from 1981, this time with endosulfan applied in addition to dieldrin. As a result, tsetse populations reduced by $99.9 \%$ by 1989 . Both times, the flies and, therefore, the disease recovered to preintervention levels presumably because of technical difficulties and complexities of dealing with a large, entrenched tsetse population living in environmentally optimal conditions (8). Over time, ambitions for tsetse eradication were replaced with interventions to control the vector (10). Active multiagency tsetse control continued until 1998 (8).

The lack of explicit information for the prevalence of pathogens, especially in the wildlife-livestock-human interfaces, is a major drawback for effective control of AAT (11). Consequently, the recently defined progressive control pathway for AAT advocates for enhanced research to understand the risks of trypanosomosis to guide the selection of priority intervention areas as the first step toward effective control (12). For Lambwe valley, epidemiologic studies investigating the prevalence of trypanosomes are scanty and decades-old $(7,13)$. A proactive approach to updating the epidemiology of AAT is therefore critical in designing interventions in the future. Notably, available HAT data are passively and retrospectively collected from clinics and cannot sufficiently determine the state of disease; studies are required to affirm the absence of livestock reservoirs for the causative agents for HAT.

Sensitive and specific tools are critical for accurately diagnosing trypanosomes and describing the prevalence. Traditionally, microscopy has been used for trypanosome detection in the field (14). This method involves blood concentration in a microhematocrit capillary tube followed by an examination of buffy coats. Despite being simple and inexpensive, the method is unreliable for immature forms and less sensitive in samples with low parasitemia and trypanosome co-infections (15). The advent of polymerase chain reaction (PCR) and the increased development of molecular markers that target different regions of the trypanosome genome improved the sensitivity significantly (16). Some of the molecular targets that are currently used to detect Trypanosome species include (i) the internal transcribed spacer (ITS) because it is highly conserved and has different size variability, which allows trypanosome identification and sub-grouping (16); (ii) the glyceraldehyde phosphate dehydrogenase (GAPDH), a housekeeping gene, which is more convenient for extensive phylogenetic analysis and, thus, a better marker for novel species identification (17); and (iii) the small subunit (SSU), 18S, and the large subunit (LSU), 28S rRNA genes (18). Historically, studies in Lambwe valley were based on microscopy $(7,13)$.

In December of 2019, we responded to distress calls from the county government of Homa Bay, smallholders in Lambwe valley, and a local non-governmental organization citing a suspected outbreak of AAT and possible HAT cases. The main symptoms in cattle reported included staring coat, swollen lymph nodes, lethargy, lacrimation, and emaciation. These symptoms are non-specific and also associated with helminthosis, malnutrition, anaplasmosis, and other tick-borne diseases (19). We implemented a large study investigating the molecular epidemiology of tick-borne pathogens and found a $78.5 \%$ prevalence of tick-borne pathogens (20), including a novel Anaplasma spp. with unknown pathogenicity to livestock or humans. By combining microscopic and PCR-High-Resolution Melting (HRM) analysis (21), this cross-sectional study aimed to assess the agreement of these assays, determine the prevalence of bovine trypanosomosis, identify risk factors, and investigate the occurrence of potentially zoonotic species in cattle in the historical focus of Lambwe valley.

\section{MATERIALS AND METHODS}

\section{Study Area and Setting}

The study was implemented in Lambwe Valley, in village clusters around the RNP (Figure 1). Lambwe Valley (latitude $0^{\circ} 38^{\prime}$ $35.52^{\prime \prime} \mathrm{S}$, longitude $\left.34^{\circ} 16^{\prime} 48^{\prime \prime} \mathrm{E}\right)$ is located south of the equator in Homa Bay County, Kenya at 1,200-1,600 m above sea level. The valley extends over $350 \mathrm{~km}^{2}$ and hosts RNP, a wildlife protectorate of $120 \mathrm{~km}^{2}$. The terrain consists of rolling grasslands with open woodland and thickets dominated by acacia and various grass species. The soil is predominantly black cotton, and the climate is hot and humid, with an average annual air temperature of $25^{\circ} \mathrm{C}$. Rainfall is bimodal, peaking in April-June and September-November. The dry and hot 


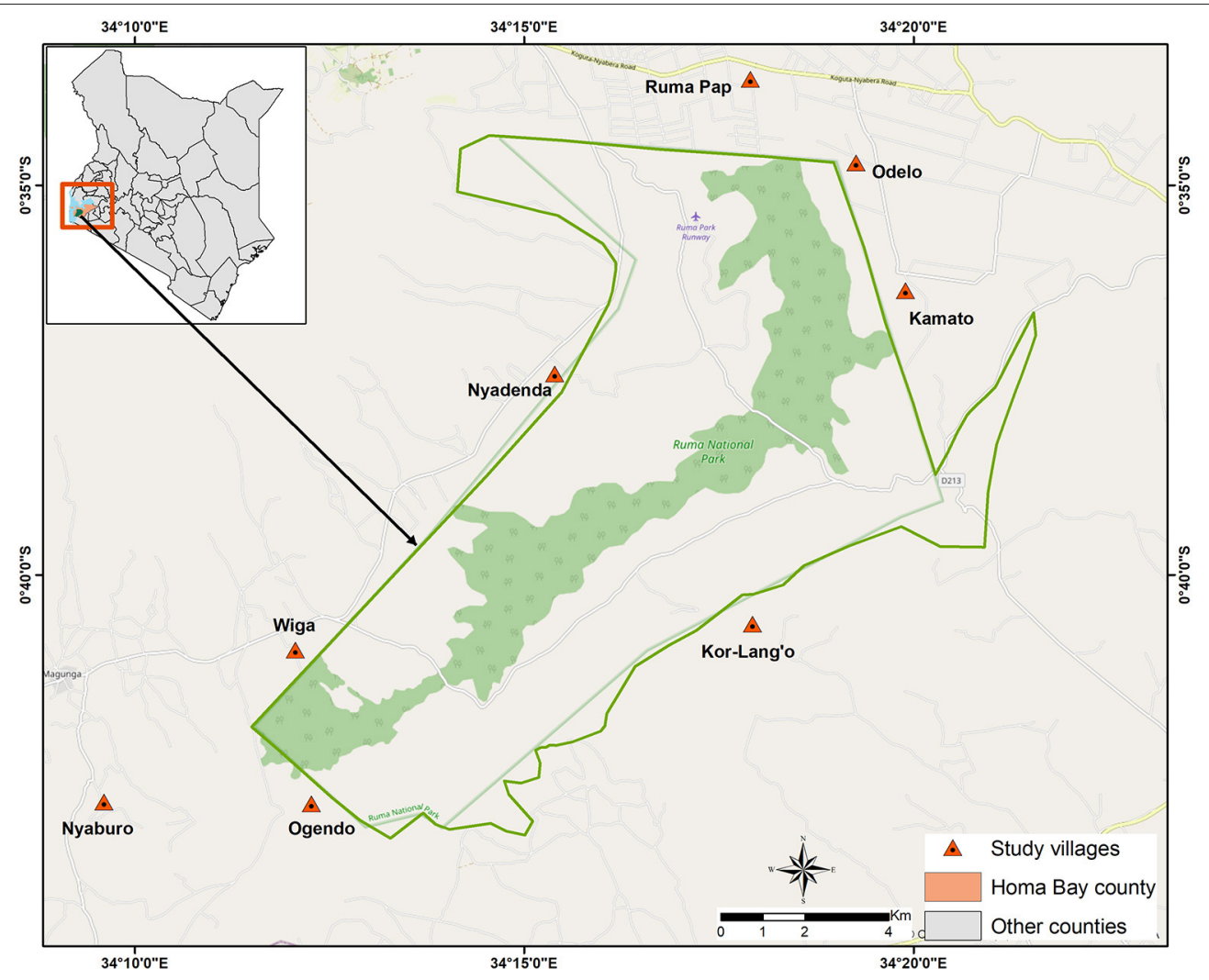

FIGURE 1 | Map of the study area indicating villages where cattle were sampled.

periods lie between January and March (22). The community in Lambwe Valley practices subsistence farming, fishing, and animal husbandry. In the park, the primary grazing and browsing wild ruminant populations consist of roan antelope (Hippotragus equinus langheldi), Jackson's hartebeest (Alcelaphus buselaphus Jacksonii), oribi (Ourebia ourebi), and Rothschild giraffes (Giraffa camelopardalis rothschildi). The indigenous zebu cattle breed is the dominant domestic species, followed by small ruminants. Livestock grazes in the open fields extending to the park's fence, thus creating an interface for interaction between wildlife and livestock. The valley is infested by G. pallidipes, the major vector for African animal trypanosomosis. G. fuscipes fuscipes distribution is limited to the lakeshore and riverine forest habitat.

\section{Cattle Herds, Sample Size Estimation, and Sampling Method}

We used a cross-sectional design with stratified one-stage cluster sampling. Details of the design and setting were described in our previous study (20). Data were collected between December 2018 and February 2019. The source population was defined as all cattle reared in the wildlife-human-livestock interface of the Lambwe valley so that all zebu cattle within a $5-\mathrm{km}$ radius from the park's fence were eligible for inclusion. The construction of a sampling frame was not possible due to the lack of reliable cattle demographic data. Therefore, all herds that voluntarily responded to a mobilization drive by the Kenya
Tsetse and Trypanosomiasis Eradication Council were sampled. Administrative boundaries are often not epidemiologically meaningful for vector-borne diseases such as trypanosomosis. Considering this, we created a grid based on a $100-\mathrm{km}^{2}$ area around the park $(\sim 1 / 3$ of the valley) and divided the cattle population into $353-\mathrm{km}^{2}$ grids, which later was named after the nearest village. Therefore, the primary sampling frame was a list of spatial clusters "villages" where herds of cattle are kept. Information on the total number of herds in the study area was missing, and therefore all herds were sampled. No animal was sampled within the park or where there was no human settlement. The workflow, study design, and sampling approach are outlined in Figure 2.

Indigenous zebu cattle that were at least 1 year old and managed in smallholder farms in the wildlife-livestock interface of the Lambwe Valley were considered eligible for the study. This age category is highly likely to interact with other herds or wildlife at watering points and during grazing, thus amenable to surveillance in the area. Sample size determination was based on one-stage cluster sampling using previously described methods (23-25).

The sample size to estimate the prevalence with a specified precision is given by:

$N=g c=P(1-\mathrm{P}) \mathrm{D} /[(\mathrm{SE})]^{\wedge} 2$ (Equation 1$)$, where $\mathrm{N}$ is the sample size, $\mathrm{P}$ is the prevalence, $\mathrm{D}$ is the design effect, $\mathrm{SE}$ is the standard error of an estimated proportion $\mathrm{P}, \mathrm{g}$ is the average 


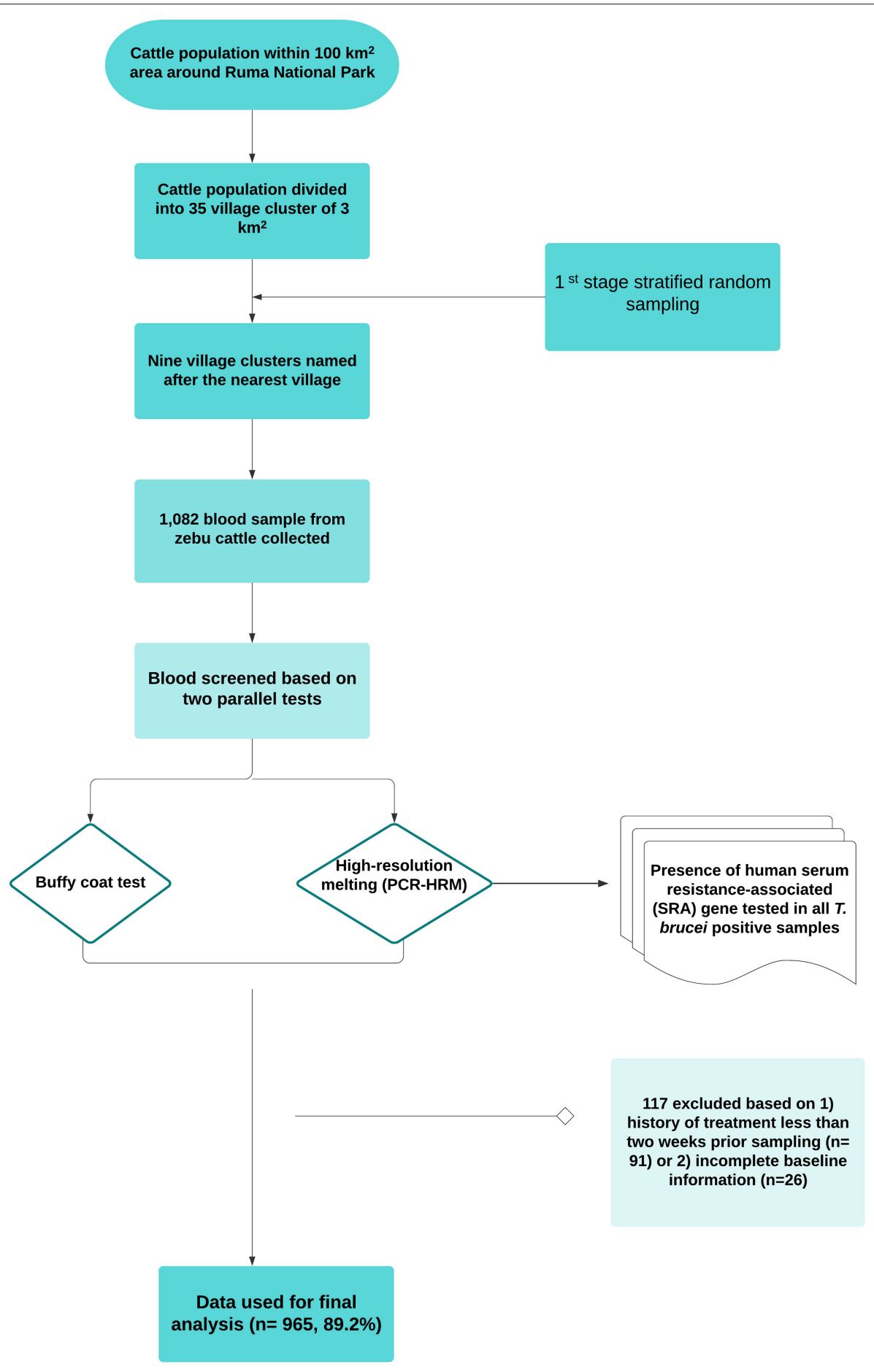

FIGURE 2 | Workflow of the study design and sampling.

number of animals sampled per cluster, and $\mathrm{c}$ the number of clusters sampled. The design effect was given by the next formula (23): $\mathrm{D}=1+(\mathrm{g}-1)$ ICC (Equation 2).

We restricted the number of sampled villages (clusters) to $25 \%(c=9)$ of 35 village clusters. The selection of these villages was first made randomly. The final listing of villages was done after accounting for accessibility. We used an intra-cluster correlation (ICC) value of 0.13 for Trypanosoma congolense from previous studies (26). The ICC is a measure of homogeneity of clustered data. Considering the possibility to collect a maximum of 100 samples by a team of six people per day per cluster, $\mathrm{D}$ was calculated as 13.87 (Equation 2). Molecular prevalence 
TABLE 1 | List of primers used for trypanosome species and SRA gene identification.

\begin{tabular}{|c|c|c|c|c|c|}
\hline Target gene & Primer & Primer sequence & Trypanosome species & Amplicon size (bp) & References \\
\hline \multirow[t]{3}{*}{$18 S$} & 18S-3F & GACCRTTGTAGTCCACACTG & T. congolense & 233 & $(18)$ \\
\hline & $18 S-4 R$ & CCСССTGAGACTGTAACCTC & T. brucei & 234 & \\
\hline & & & T. vivax & 199 & \\
\hline \multirow[t]{2}{*}{ TBR } & TBR-1 & CGAATGAATATTAAACAATGCGCAGT & T. brucei subspecies & 177 & (29) \\
\hline & TBR-2 & AGAACCATTTATAGCTTTGTTGC & & & \\
\hline \multirow[t]{2}{*}{ SRA } & SRA-A & GACAACAAGTACCTTGGCGC & T.b. rhodesiense & 460 & $(30)$ \\
\hline & SRA-E & TACTGTTGTTGTACCGCCGC & & & \\
\hline \multirow[t]{2}{*}{ SRA } & B537 & CCATGGCCTITGACGAAGAGCCCG & T.b. rhodesiense & 743 & (31) \\
\hline & B538 & CTCGAGTITGCTITCTGTATIITCCC & & & \\
\hline
\end{tabular}

information for trypanosomosis is limited in the study area. Therefore, the study assumed a prevalence $(P)$ of $17 \%$ from a similar Maasai Steppe wildlife-livestock interface in Tanzania (27). With an expected prevalence of $17 \%$, a cluster size of 9 and a desired precision of $5 \%$, a total sample size of 783 animals was estimated. The study was announced to farmers for sensitization through local radio, accounting for a $15 \%$ non-response rate. To consider sample size for non-response rate:

$N=$ (Sample size calculated) $/(1$ - non-response rate) (Equation 3). The above equations gave an estimated sample size of 921. A total of 1,082 blood samples were collected. However, 117 samples were excluded based on (1) history of treatment $<2$ weeks prior to sampling $(n=91)$ and (2) incomplete baseline information $(n=26)$. The final dataset consisted of a total of 952 cattle.

Epidemiological data on potential risk factors were collected from each sampled household using a questionnaire. The following variables were captured: sex, herd size, and village and homestead distance from the park's fence. Distance from the park was used as a conservative approach to identifying areas with greater risk for trypanosomosis. The position of the homestead was marked by GPS (Garmin GPS). Furthermore, herd husbandry practices including trypanocidal drug usage, sources of drug, treatment frequency, and personnel involved in the treatment of cases were also collected.

\section{Blood Collection and Processing}

During the survey, two blood samples from each cattle were taken in the early morning. The specimen consisted of blood samples collected from (1) the marginal ear vein to determine the level of anemia level, examination of buffy coat, and the preparation of thin blood films; and (2) the jugular vein blood for the molecular detection of trypanosomes by PCR-HRM.

Each animal was assessed for anemia by measuring packed cell volume (PCV) using the micro-hematocrit method. Briefly, capillary blood was drawn into EDTA microhematocrit tubes and centrifuged at $13,000 \mathrm{~g}$ for $10 \mathrm{~min}$. Then, PCV levels were calculated using the Hawksley hematocrit reader.

Detection of trypanosome species was performed by two parallel tests, buffy coat technique (14) and PCR-HRM (28). Morphological identification of Trypanosomes was conducted by microscopic examination of Giemsa-stained fixed thin blood smear. For molecular detection of trypanosomes, about $4 \mathrm{ml}$ of blood was collected from the jugular vein of each cattle using sterile vacutainer needles and EDTA vacutainers. A unique animal's number identified each tube. Blood in the EDTA vacutainers was transferred into uniquely labeled cryovials, stored in liquid nitrogen, and transported to icipe's Martin Lüscher-Emerging Infectious Diseases (ML-EID) Laboratory for molecular analysis.

\section{Real-Time PCR and High-Resolution Melting Analysis}

DNA was extracted from whole blood samples using the Bioline Isolate II genomic DNA kit (Meridian Life Science, Memphis, USA) as described by the manufacturer. A single-plex PCR was performed to screen for the presence of Trypanosoma spp. using $18 \mathrm{~S}$ rRNA trypanosome-specific primers, as shown in Table 1. PCR was carried out in a $10-\mu l$ volume consisting of $1 \mu \mathrm{l}$ of the extracted DNA template, $2 \mu \mathrm{l} 5 \times$ H.O.T. FIREPol ${ }^{\circledR}$ EvaGreen H.R.M. Mix (Solis BioDyne, Tartu, Estonia), $0.5 \mu \mathrm{l}$ of each $10 \mu \mathrm{M}$ forward and reverse primers for the respective genusspecific reactions, and $6 \mu \mathrm{l}$ of PCR water. The PCR amplification assays were done in QuantStudio 3 (Applied Biosystems) HRM capable thermocycler. The amplification condition involved an initial activation of the polymerase enzyme at $95^{\circ} \mathrm{C}$ for $15 \mathrm{~min}$, followed by 40 cycles of denaturation at $94^{\circ} \mathrm{C}$ for $30 \mathrm{~s}$, annealing at $62^{\circ} \mathrm{C}$ for $30 \mathrm{~s}$, extension at $72^{\circ} \mathrm{C}$ for $30 \mathrm{~s}$, and final extension steps at $72^{\circ} \mathrm{C}$ for $10 \mathrm{~min}$. The fluorescence data were captured at the end of every cycle at the extension stage on the green channel (excitation at $470 \mathrm{~nm}$ and emission at $510 \mathrm{~nm}$ detection spectrum). HRM analysis was performed post PCR where the PCR amplicons were gradually dissociated at $0.1^{\circ} \mathrm{C}$ temperature increments from 75 to $97^{\circ} \mathrm{C}$ with fluorescence acquisition data captured every $2 \mathrm{~s}$. The unknown PCR samples were identified by comparing the different melting profiles with the positive controls using the HRM analysis software version 2.1.0 (Qiagen).

\section{SRA PCR for Detection of T.b. rhodesiense in Cattle PCR Confirmation of T. brucei Subspecies}

To ascertain whether the HRM positive samples were indeed T. brucei subspecies of trypanosome, T. brucei 18S PCR-HRM positive samples were amplified by TBR1/2 primers specific for 
T. brucei subspecies (Table 1). PCR amplification was carried out in $10 \mu \mathrm{l}$ volume containing $3.0 \mu \mathrm{l}$ of nuclease-free water, $5.0 \mu \mathrm{l}$ of HotStarTaq Master Mix (Qiagen), $0.5 \mu \mathrm{l}$ of $10-\mu \mathrm{m}$ primers, and $1.0 \mu \mathrm{l}$ of DNA template. Negative control was included to confirm the absence of contamination. The amplification was carried out in ProFlex PCR System (Applied Biosystems) with an initial denaturation step at $95^{\circ} \mathrm{C}$ for 15 min followed by 35 cycles of denaturation at $95^{\circ} \mathrm{C}$ for $1 \mathrm{~min}$, annealing at $55^{\circ} \mathrm{C}$ for $1 \mathrm{~min}$, and extension at $72^{\circ} \mathrm{C}$ for $1 \mathrm{~min}$ and final elongation at $72^{\circ} \mathrm{C}$ for $5 \mathrm{~min}$. The PCR amplicons were visualized in $2.0 \% \mathrm{w} / \mathrm{v}$ agarose gel stained with $5.0 \mu \mathrm{l}$ of $10 \mathrm{mg} / \mathrm{ml}$ of ethidium bromide.

\section{SRA PCR for Detection of T.b. rhodesiense in Cattle} Amplification of the SRA gene was conducted using the primers B537/B538 and SRA-A/SRA-E (Table 1) specific for T.b. rhodesiense. The amplification was performed in a $10-\mu 1$ reaction volume containing $3.0 \mu \mathrm{l}$ of nuclease-free water, $5.0 \mu \mathrm{l}$ of HotStarTaq Master Mix (Qiagen), $0.5 \mu \mathrm{l}$ of $10-\mu \mathrm{m}$ primers, and $1.0 \mu \mathrm{l}$ of purified DNA template. The amplification profile using SRA-A/SRA-E was as follows: initial denaturation step at $95^{\circ} \mathrm{C}$ for $15 \mathrm{~min}$ followed by 45 cycles of denaturation at $95^{\circ} \mathrm{C}$ for $1 \mathrm{~min}$, annealing at $68^{\circ} \mathrm{C}$ for $1 \mathrm{~min}$ and extension at $72^{\circ} \mathrm{C}$ for $1 \mathrm{~min}$, and final elongation at $72^{\circ} \mathrm{C}$ for $10 \mathrm{~min}$. Detection of T.b. rhodesiense SRA gene using the B537/B538 primer set involved an initial denaturation step at $95^{\circ} \mathrm{C}$ for $15 \mathrm{~min}$ and 10 cycles at $94^{\circ} \mathrm{C}$ for $20 \mathrm{~s}, 55^{\circ} \mathrm{C}$ for $30 \mathrm{~s}$, and $72^{\circ} \mathrm{C}$ for $1 \mathrm{~min}$ followed by 30 cycles at $95^{\circ} \mathrm{C}$ for $20 \mathrm{~s}$ and $64^{\circ} \mathrm{C}$ for $30 \mathrm{~s}$, and extension at $72^{\circ} \mathrm{C}$ for 1-min extension time was increased by $2 \mathrm{~s}$ per cycle and final elongation at $72^{\circ} \mathrm{C}$ for $10 \mathrm{~min}$. All amplification was performed in ProFlex PCR System (Applied Biosystems). The PCR amplicons were visualized in $2 \% \mathrm{w} / \mathrm{v}$ agarose gel stained with $5.0 \mu \mathrm{l}$ of 10 $\mathrm{mg} / \mathrm{ml}$ of ethidium bromide.

\section{Data Management and Analysis}

A database consisting of a questionnaire and molecular data was established in Microsoft. Excel (Microsoft ${ }^{\circledR}$ Excel, Washington). Individual- and herd-level information, including animal sex, age, animal weight, anemia status, herd size, village name, the distance of homestead from the park's fence, drug use (type and frequency), and infection status, was recorded. Distance of homestead from the park's fence was measured using a handheld GPS device. Age of cattle was categorized into $\leq 2$ (calves and weaners) and $>2$ (adults) years and herd size was categorized into small ( $<10$ head of cattle) or medium ( $\geq 10$ head of cattle). Anemia status was categorized into anemic $(\mathrm{PCV} \leq 24)$ and normal $(\mathrm{PCV}>24)$. After checking and variable coding, data were transferred to SPSS version 25 (I.B.M. Corp, Armonk, NY) for descriptive statistics and univariable regression. The degree of agreement between BCT and PCR-HRM techniques was determined in matching blood samples by calculating kappa $(\kappa)$ values in SPSS 25 suite. $\kappa$ values express the agreement beyond chance and were interpreted according to Altman (32).
A

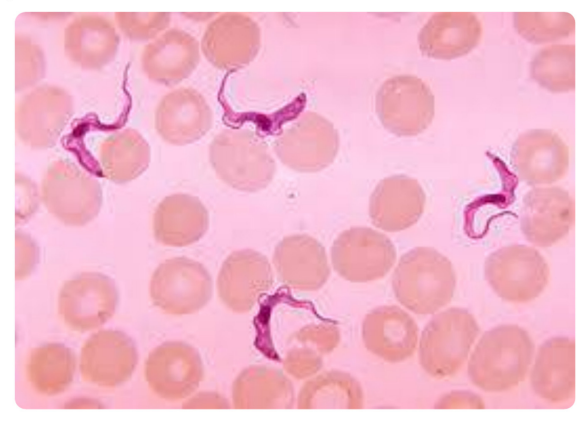

Buffy Coat Test

C

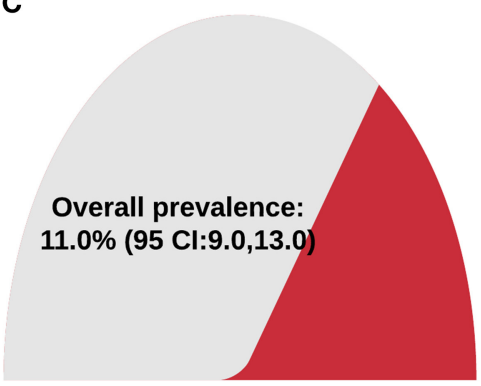

B

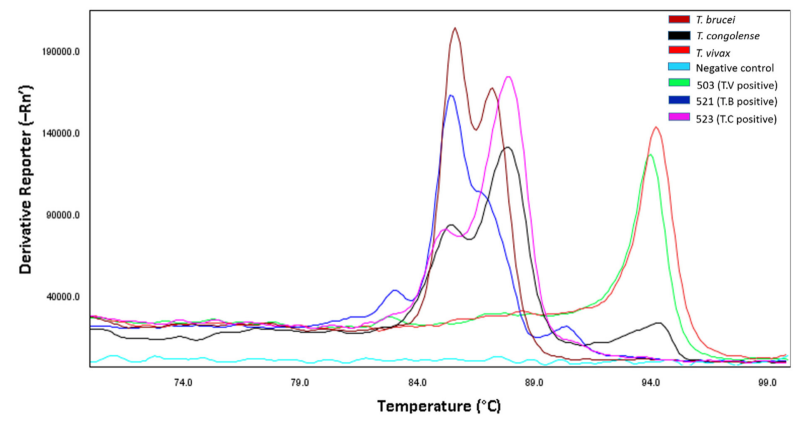

PCR-HRM

D

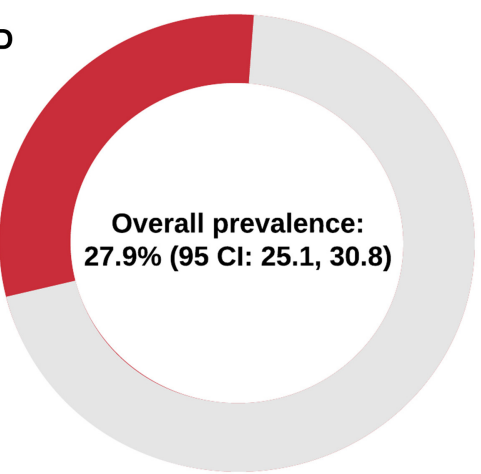

FIGURE 3 | Trypanosome species as identified by microscopy (A), PCR-HRM (B), and prevalence (C,D). 
TABLE 2 | Comparison of diagnostic test results obtained by microscopic (BCT) and molecular method (PCR-HRM).

\begin{tabular}{|c|c|c|c|c|c|c|c|c|}
\hline \multirow[t]{2}{*}{ Microscopy (BCT) } & \multicolumn{7}{|c|}{ PCR-HRM } & \multirow[t]{2}{*}{ Total (\%) } \\
\hline & Tb & Tc & Tt & Tv & $\mathrm{Tb} / \mathrm{Tv}$ & Tc/Tv & Negatives & \\
\hline $\mathrm{Tb}$ & $1^{\star}$ & 1 & 1 & 0 & 0 & 0 & 1 & $4(0.4)$ \\
\hline Tc & 8 & $27^{\star}$ & 0 & 6 & 4 & 0 & 32 & $77(8.1)$ \\
\hline $\mathrm{Tt}$ & 0 & 0 & 0 & 0 & 0 & 0 & 1 & $1(0.1)$ \\
\hline TV & 1 & 1 & 0 & $1^{\star}$ & 0 & 0 & 16 & $19(2.0)$ \\
\hline $\mathrm{Tb} / \mathrm{Tv}$ & 0 & 0 & 0 & 0 & 0 & 0 & 0 & $0(0.0)$ \\
\hline $\mathrm{Tc} / \mathrm{TV}$ & 0 & 1 & 0 & 0 & 0 & 0 & 2 & $3(0.3)$ \\
\hline Negatives & 59 & 91 & 11 & 72 & 15 & 4 & $633^{*}$ & $847(89.0)$ \\
\hline Total (\%) & $54(5.7)$ & 117 (12.3) & $12(1.3)$ & $60(6.3)$ & $19(2.0)$ & $4(0.4)$ & $686(72.1)$ & 952 \\
\hline
\end{tabular}

Tb, Trypanosoma brucei; Tc, T. congolense; Tt, T. theileri; Tv, T. vivax; Tb/TV, mixed infection of T. brucei and T. vivax; Tc/Tv, mixed infection of T. congolense and T. vivax.

${ }^{*}$ Number of positive or negative samples detected by both BCT and PCR-HRM methods.

The prevalence of each trypanosome species was calculated by dividing the number of positive samples by the total animal sample during the study period. Overall and specieslevel prevalence and 95\% confidence intervals were calculated as Wilson Score intervals. The relationship between the presence of trypanosomes and putative risk factors was modeled using univariable logistic regression models. The odds ratio with its $95 \%$ confidence interval was used as a summary statistic.

\section{RESULTS}

\section{Parasitological and Molecular Detection of Trypanosome Infection}

A total of 952 blood samples were tested in nine village clusters parallelly by BCT microscopy and PCR-HRM. The samples were all local zebu cattle from 164 herds with an average herd size of seven and were maintained under a free-range grazing system. The distance range between the chosen village clusters and the RNP fence was between 0 (homesteads within the park's fence) and 4,461 m (median $806 \mathrm{~m}$ ). Parasitological and molecular test results are summarized in Figure 3 and Table 2. Four trypanosome species, T. brucei brucei, T. congolense, $T$. theileri, and T. vivax, were present in the study area. The overall trypanosome infection prevalence using BCT and PCR-HRM tests was $11.0 \%$ (95\% CI: $9.0-13.0)$ and $27.9 \%$ (95\% CI: $25.1-$ 30.8), respectively (Figure 3, Table 2).

BCT detection showed 105 animals infected by one or more species of trypanosomes, and $T$. congolense was the most prevalent species (Table 2). PCR-HRM detection showed 266 infected animals. Like the BCT method, the most prevalent trypanosome species by PCR-HRM was T. congolense $(12.7 \%$, 95\% CI: 10.6-14.8), followed by T. vivax (8.7\%, 95\% CI: 6.910.5), and T. brucei brucei (7.7\%, 95\% CI: 6.0-9.4). Infection with single trypanosome species accounted for most infections ( $243 / 266$ by PCR-HRM and $102 / 105$ by BCT method). The prevalence of mixed infection was $2.3 \%$ by PCR-HRM and was significantly higher than the BCT method (0.3\%). More than $82 \%$ (19 out of 23) of mixed infection identified by PCR-HRM was due to T. vivax and T. brucei brucei. Four samples were co-infected by
TABLE 3 | Prevalence of Trypanosome species in naturally infected cattle in Lambwe valley, and the sensitivity and specificity of BCT, using PCR-HRM as a reference test.

\begin{tabular}{|c|c|c|c|c|}
\hline \multirow[t]{2}{*}{ Trypanosoma } & & \multirow{2}{*}{$\begin{array}{c}\text { Point } \\
\text { estimates }\end{array}$} & \multicolumn{2}{|c|}{$95 \% \mathrm{Cl}$} \\
\hline & & & Lower & Upper \\
\hline \multirow[t]{3}{*}{ T. brucei } & Prevalence & 7.7 & 6.0 & 9.4 \\
\hline & Sensitivity & 0.014 & 0.0003 & 0.074 \\
\hline & Specificity & 0.997 & 0.99 & 0.999 \\
\hline \multirow[t]{3}{*}{ T. congolense } & Prevalence & 12.7 & 10.6 & 14.8 \\
\hline & Sensitivity & 0.231 & 0.16 & 0.32 \\
\hline & Specificity & 0.94 & 0.92 & 0.95 \\
\hline \multirow[t]{3}{*}{ T. vivax } & Prevalence & 8.7 & 6.9 & 10.5 \\
\hline & Sensitivity & 0.012 & 0.0003 & 0.065 \\
\hline & Specificity & 0.976 & 0.963 & 0.985 \\
\hline \multirow[t]{3}{*}{ T. theileri } & Prevalence & 1.3 & 0.6 & 2.0 \\
\hline & Sensitivity & 0 & 0 & 0.27 \\
\hline & Specificity & 0.999 & 0.99 & 1 \\
\hline \multirow[t]{5}{*}{ Overall } & Prevalence & 27.9 & 25.1 & 30.8 \\
\hline & Sensitivity & 0.2 & 0.15 & 0.25 \\
\hline & Specificity & 0.92 & 0.90 & 0.94 \\
\hline & $\mathrm{PPV}^{*}$ & 0.495 & 0.44 & 0.56 \\
\hline & $\mathrm{NPV}^{*}$ & 0.747 & 0.74 & 0.75 \\
\hline
\end{tabular}

${ }^{*} P P V$, positive predictive value; NPV, negative predictive value.

T. congolense and T. vivax. All the three mixed infections detected by BCT microscopy were due to T. congolense and T. vivax.

Performance of the BCT and PCR-HRM was assessed in 952 matching blood samples. The degree of agreement was found to be poor (72\%, Cohen's $k=0.145,95 \%$ CI: $0.083-0.207)$. Comparing PCR-HRM method as a reference, BCT microscopy showed poor sensitivity to detect all species. Nonetheless, the specificity was well above $90 \%$ (Table 3). BCT has a sensitivity of $20 \%$ (95\% CI: $15-25 \%$ ), a specificity of $92 \%$ (95\% CI: $90-$ 94), a positive predictive value of $49.5 \%$ (95\% CI: $44-56)$, and 
TABLE 4 | Risk factors associated with trypanosome infection status using PCR-HRM as a reference test.

\begin{tabular}{|c|c|c|c|c|c|c|c|c|c|}
\hline \multirow[t]{2}{*}{ Risk factors } & \multirow[t]{2}{*}{ Category level } & \multirow[t]{2}{*}{$n^{a}$} & \multirow[t]{2}{*}{ Overall prevalence $(95 \% \mathrm{Cl})$} & \multicolumn{2}{|c|}{ T. congolense } & \multicolumn{2}{|c|}{ T. vivax } & \multicolumn{2}{|c|}{ T. brucei } \\
\hline & & & & Prevalence (\%) & $95 \% \mathrm{Cl}$ & Prevalence (\%) & $95 \% \mathrm{Cl}$ & Prevalence (\%) & $95 \% \mathrm{Cl}$ \\
\hline \multirow[t]{9}{*}{ Village } & Kor-Lango & 56 & $10.7(5.0,21.5)$ & 1.8 & $0.3,9.4$ & 3.6 & $0.9,12$ & 1.8 & $0.3,9.4$ \\
\hline & Odelo & 68 & $19.1(11.5,30.0)$ & 7.4 & $3.2,16.1$ & 4.4 & $1.5,12.2$ & 7.4 & $3.2,16.1$ \\
\hline & Nyadenda & 200 & $23.0(17.7,29.3)$ & 15.0 & 10.7, 20.6 & 2.5 & $1.1,5.7$ & 4.5 & $2.4,8.3$ \\
\hline & Gendo & 68 & $23.5(15.0,34.9)$ & 8.8 & $4.1,17.9$ & 10.3 & $5.1,19.8$ & 1.5 & $0.3,7.9$ \\
\hline & Wiga & 68 & $23.5(15.0,34.9)$ & 8.8 & $4.1,17.9$ & 5.9 & $2.3,14.2$ & 1.5 & $0.3,7.9$ \\
\hline & Kamato & 190 & $27.9(22.0,36.7)$ & 16.3 & $11.7,22.2$ & 3.7 & $1.8,7.4$ & 8.4 & $5.3,13.2$ \\
\hline & Nyaburo & 115 & $29.6(22.0,38.5)$ & 10.4 & $6.1,17.4$ & 12.2 & $7.4,19.4$ & 13.0 & $8.1,20.4$ \\
\hline & Ruma Pap & 122 & $33.6(25.8,42.4)$ & 12.3 & $7.6,19.3$ & 20.5 & $14.3,28.5$ & 10.7 & $6.3,17.4$ \\
\hline & Ogendo & 65 & $63.1(50.9,73.8)$ & 23.1 & $14.5,34.6$ & 24.6 & $15.8,36.3$ & 18.5 & $10.9,29.6$ \\
\hline \multicolumn{10}{|l|}{ Herd size } \\
\hline & Small & 513 & $30.2(26.4,34.3)$ & 13.5 & $10.8,16.7$ & 10.3 & $7.9,13.3$ & 7.8 & $5.8,10.4$ \\
\hline & Medium & 111 & $25.3(21.5,29.6)$ & 11.8 & $9.2,15.2$ & 6.8 & $4.8,9.6$ & 7.5 & $5.4,10.4$ \\
\hline \multicolumn{10}{|l|}{ Sex } \\
\hline & Male & 461 & $26.9(23.1,31.1)$ & 12.6 & $9.9,15.9$ & 7.8 & $5.7,10.6$ & 6.5 & $4.6,9.1$ \\
\hline & Female & 491 & $28.9(25.1,33.1)$ & 12.8 & $10.2,16.1$ & 9.6 & $7.3,12.5$ & 8.8 & $6.6,11.6$ \\
\hline \multicolumn{10}{|l|}{ Age } \\
\hline & Calves and weaners & 158 & $24.1(18.1,31.3)$ & 8.2 & $4.9,13.6$ & 10.1 & $6.3,15.8$ & 8.2 & $4.9,13.6$ \\
\hline & Adults & 792 & $28.8(25.7,32.0)$ & 13.6 & $11.4,16.2$ & 8.5 & $6.7,10.6$ & 7.6 & $5.9,9.6$ \\
\hline \multicolumn{10}{|l|}{ Distance } \\
\hline & $\leq 1 \mathrm{~km}$ & 525 & $28.4(24.7,32.4)$ & 14.3 & $11.6,17.5$ & 8.4 & $6.3,11.1$ & 6.5 & $4.7,8.9$ \\
\hline & $>1 \mathrm{~km}$ & 427 & $27.4(23.4,31.8)$ & 10.8 & $8.2,14.1$ & 9.1 & $6.8,12.2$ & 9.1 & $6.8,12.2$ \\
\hline
\end{tabular}

negative predictive value of $74.5 \%$ (95\% CI: 74-75). Trypanosoma vivax and T. brucei brucei were the species most missed by BCT microscopy examination.

SRA-PCR analysis showed that none of the $T$. brucei subspecies positive samples was positive for the human-infective trypanosome species (T.b. rhodesiense).

Presence of trypanosomes was associated with anemia level $\left(\chi^{2}=4.563, d f=1, p=0.038\right)$. While infection with the $T$. vivax and T. brucei subgroup was not associated with PCV level, $44 \%$ of T. congolense infected cattle were below $24 \%$, and this proportion was significantly higher than negative cattle $\left(28.5 \%, \chi^{2}=11.417\right.$, $p=0.001)$ (Supplementary Table 1).

\section{Association of Putative Risk Factors With Trypanosome Infection}

Table 4 presents the results from the univariable logistic regression analysis of the association between individual-level exposure and trypanosome infection status.

Overall, the prevalence of trypanosomosis was higher in small herds $(30.2 \%)$, female cattle $(28.9 \%)$, adult cattle $(28.8 \%)$, and in homesteads $<1 \mathrm{~km}$ from the park $(28.4 \%)$. However, the association was not statistically significant.

The prevalence of trypanosomes varied between the village clusters significantly $(p<0.001)$. The distribution of the three pathogenic trypanosome species across the spatially clustered villages is as shown in Figure 4. The overall trypanosomosis prevalence ranged from 10.9 to $63.1 \%$. The four villages with the higher trypanosome prevalence were Ogendo (63\%), Ruma
Pap (33.6\%), Nyaburo (29.6\%), and Kamato (27.9\%). The lowest infection rate was found in Kor-Lango (10.7\%).

The risk factor analysis did not include $T$. theileri due to the availability of sufficient data to perform a risk factor analysis.

\section{DISCUSSION}

We found that the prevalence of bovine trypanosomosis in Lambwe valley was high and comparable to previous years. The BCT estimate of $11 \%$ prevalence is within the range of earlier studies and the historical data for the area. Robson and Ashkar estimated a prevalence rate of $17 \%$ in 1972 (7). Twenty years later, following periods of tsetse control and increasing human habitation of the valley (8), Nesbitt et al. (13) reported a lower rate for AAT at 5.6\% in 1991. The differences in prevalence over time could be due to varied approaches to sampling, the effect of interventions, or just the characteristic flare-up and quiescence of trypanosomosis in the Lambwe valley (8).

With a molecular prevalence of $27.9 \%$, our results demonstrated that cattle around RNP remain at a relatively high risk of AAT. The risk for AAT around wildlife interfaces in Kenya is varied, with the highest molecular prevalence estimated at $33.9 \%$ recorded in smallholder farms at the interface of the Shimba Hills (33). A comparatively lower molecular prevalence of $17.2 \%$ was reported for the Maasai Steppe in Tanzania (27). However, the prevalence rates for bovine trypanosomosis in the Lambwe valley at the time of this study were in agreement with previously recorded rates for the area $(7,13)$ or that of other 


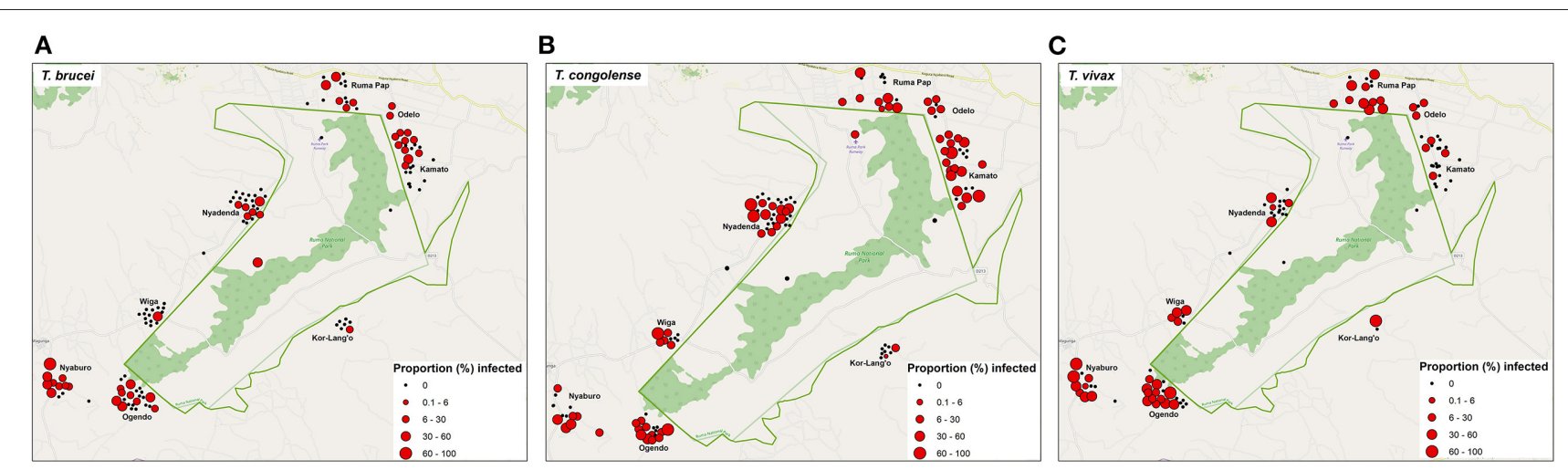

FIGURE 4 | Distribution map showing the pathogenic trypanosome species detected and overlay with the proportion of infected cattle in each homestead (A-C) as tested by PCR method.

regions endemic for the disease in Kenya (34) and in different areas (35-37). The minor discrepancies in prevalence between studies are likely associated with differences in sampling design, diagnostic method, location, and ecological factors such as wild host and farming practices.

Consistent with previous studies, the present work identified three trypanosome species that adversely affect cattle and the relatively little pathogenic species, $T$. theileri. Of these, $T$. congolense was the most important and accounted for nearly half of all infections, $45.5 \%$ (121/266). Similar to previous reports from Lambwe, the second-highest infections were of T. vivax $(31.2 \%, 83 / 266)$ and after that, T. brucei brucei $(27.4 \%, 73 / 266)(7$, 13). The role of cattle and wildlife in sustaining the sylvatic cycle of $T$. brucei rhodesiense, especially in wildlife-livestock interfaces, is well-established $(6,11,38-40)$. In a survey on small ruminants and cattle in Ngorongoro conservation in Tanzania, Ruiz et al. (39) reported that $2.1 \%$ of cattle had T. brucei rhodesiense. While Robson and Ashkar (7) recorded a 10.5\% prevalence of T.b. rhodesiense in cattle in the Lambwe valley in 1972, we found no evidence of the human infective pathogen during this study. This finding indicates that the livestock reservoir for T. brucei rhodesiense around RNP, if any, is minimal and adds evidence that the pathogen may have been eliminated from the Lambwe valley by past interventions that included intensified proactive testing and treating of human reservoirs.

This study showed considerable heterogeneity in the villages with evidence of geographical clustering of trypanosomosis. With a prevalence of $10.7 \%$, the least odds of infection were found in Kor-Lango. Though not investigated in this study, it might be attributable to variability in the local tsetse ecology. In a study implemented in Nguruman, Southwest Kenya, Odulaja et al. (41) showed that $G$. pallidipes, the same tsetse species that historically infests Lambwe valley, was highly aggregated at a scale of $4 \mathrm{~km}$ (41). Microaggregation of tsetse fly populations has been shown to correlate with the spatial prevalence of trypanosomosis (41). Kor-Lango is located in the southeastern part of the park and more than $4 \mathrm{~km}$ of other study villages.
We found that $85 \%$ of all infections occurred $<2 \mathrm{~km}$ from RNP. However, analyses of risk factors did not associate the distance of homesteads from the park with differences in infection rates. Wildlife-protected areas are known to increase the risk for tsetse bites and trypanosomal disease (8). Indeed, previous studies in Lambwe have attributed the endemicity of African trypanosomosis to the presence of wild animal reservoir for trypanosomes and a ready source of blood meals for vector populations (8). The household locations used in risk factor analysis do not reflect cattle movement relative to the park during tsetse pick biting hours, and this might have weakened the association if grazing lands were different from the location of homesteads. Human occupation of Lambwe valley has steadily increased with consequent tsetse habitats destruction beyond protected area (42). The farmers who responded to this sampling effort lived near RNP and within the daily flight range of tsetse (43). It is plausible that this bias in the drive of farmers responding to the call reflects their disproportionate exposure and higher risk for AAT. The putative risk factors of animal age, sex, and herd size showed no significant association with the trypanosome species infection.

Our findings show that the BCT microscopic method can underestimate the detection of trypanosomes in cattle. We reported a more than 2-fold lower prevalence of AAT with BCT than PCR-HRM. Furthermore, using microscopy, we missed several infections with T. vivax, T. brucei brucei, and mixed trypanosome species infections when screening with BCT. For its relative affordability and ease of use, especially in field conditions, microscopy remains the primary choice for detecting trypanosomes in blood samples (44). Accordingly, most previous studies in Lambwe were based on microscopic examination of thick blood smears or BCT (13) and could have reported lower prevalence of trypanosomes. The use of PCR as a diagnostic tool has been shown to increase the number of trypanosome infections detected in cattle by at least 2 -fold (45-48) and may provide reliable information on prevalence. Lower detection with microscopy relative to the molecular-based technique could 
result from some sampled cattle at the chronic infection stage when parasitemia is typically lower than an acute clinical stage.

Our result showed that infected cattle were significantly anemic compared to non-infected cattle. Reductions in PCV were due to infection with $T$. congolense but not T. vivax and T. brucei brucei. We observed that $44 \%$ of $T$. congolense infected cattle were anemic $(\mathrm{PCV}<24 \%)$. Anemia is vital in the pathogenesis of trypanosomosis (49) and an indicator of disease severity. The parasite $T$. congolense is known to reduce the PCV or cause anemia in cattle (50). This finding, therefore, suggests that livestock are adversely affected by AAT in the Lambwe Valley and that the majority of severe infections are due to $T$. congolense infections. We also recorded significant rates of anemia in cattle not infected with $T$. congolense, with $24.9 \%$ of these recording a mean PCV of $<24 \%$. Mixed infection can increase competition for nutrients and space by trypanosomes, thus causing anemia. Though $8.7 \%$ of infected animals had mixed infections, we did not find evidence for lowered PCV due to mixed infection level. This result suggests other factors such as helminths, nutrition, and tick-borne diseases. Our other investigation related to this study showed that anaplasmosis also contributed to the anemic state of cattle in the Lambwe Valley (20).

In conclusion, our study demonstrates that control efforts likely eliminated HAT but not bovine trypanosomosis in Lambwe Valley. The risk for AAT remains high around the RNP but is underestimated in previous studies and using microscopy. Molecular diagnostics can aid accurate mapping of trypanosomosis in cattle of Lambwe Valley and enable risk-tailored interventions with potential impact on bovine trypanosomosis.

\section{DATA AVAILABILITY STATEMENT}

The original contributions presented in the study are included in the article/Supplementary Materials, further inquiries can be directed to the corresponding author/s.

\section{ETHICS STATEMENT}

The animal study strictly adhered to the experimental guidelines and procedures approved by the Institutional Animal Care and Use Committee at International Centre of Insect Physiology and Ecology (icipe) and Kenya's animal welfare laws under the Veterinary Surgeons and Veterinary Para-professionals Act, 2011 (Cap. 366). Blood samples were collected only after receiving informed verbal consent from cattle keepers. Blood samples

\section{REFERENCES}

1. Cecchi G, Paone M, Feldmann U, Vreysen MJ, Diall O, Mattioli RC. Assembling a geospatial database of tsetse-transmitted animal trypanosomosis for Africa. Parasit Vectors. (2014) 7:39. doi: 10.1186/1756-3305-7-39

2. Meyer A, Holt HR, Selby R, Guitian J. Past and ongoing tsetse and animal trypanosomiasis control operations in five African Countries: a systematic review. PLoS Negl Trop Dis. (2016) 10:e0005247. doi: 10.1371/journal.pntd.0005247 were collected by an experienced veterinarian with the aim of minimising pain and discomfort.

\section{AUTHOR CONTRIBUTIONS}

MO, DM, DG, and SK: conceptualization. PO, MO, KM, and SK: methodology. KM, PO, and SK: formal analysis. PO, MO, FM, EK, DM, and SK: investigation. MO and SK: data curation and writing-original draft preparation. SK, EK, DG, FM, and MO: writing - review and editing. DM and DG: supervision. DM and MO: project administration and funding acquisition. All authors have read and agreed to the published version of the manuscript.

\section{FUNDING}

This work was supported through the European Union's Integrated Biological Control Applied Research Programmetsetse repellent component (EU-IBCARP tsetse) awarded to the International Centre of Insect Physiology and Ecology (icipe), and grant number (IBCARP DCI-FOOD/2014/346739), the German Ministry for Economic Cooperation and Development (B.M.Z.) through the Deutsche Gesellschaft für Internationale Zusammenarbeit (G.I.Z.) ICTDL Project Contract No: 81235250 and Project No: 18.7860.2-001.00 and the DELTAS Africa Initiative grant \# DEL-15-011 to THRiVE-The DELTAS Africa Initiative is an independent funding scheme of the African Academy of Sciences (AAS)'s Alliance for Accelerating Excellence in Science in Africa (AESA) and supported by the New Partnership for Africa's Development Planning and Coordinating Agency (NEPAD Agency) with funding from the Wellcome Trust grant \# 107742/Z/15/Z. Additionally, we acknowledge institutional financial support to icipe by UK Aid from the UK Government, Swedish International Development Cooperation Agency (Sida), the Swiss Agency for Development and Cooperation (SDC), Federal Democratic Republic of Ethiopia, and the Kenyan Government. The funders had no role in study design, data collection and analysis, design, data collection and analysis, the decision to publish, or manuscript preparation.

\section{SUPPLEMENTARY MATERIAL}

The Supplementary Material for this article can be found online at: https://www.frontiersin.org/articles/10.3389/fvets. 2021.750169/full\#supplementary-material
3. Muhanguzi D, Okello WO, Kabasa JD, Waiswa C, Welburn SC, Shaw AP. Cost analysis of options for management of African Animal Trypanosomiasis using interventions targeted at cattle in Tororo District; south-eastern Uganda. Parasit Vectors. (2015) 8:387. doi: 10.1186/s13071-015-0998-8

4. WHO. Progress on Eliminating Sleeping Sickness as a Public Health Problem. (2018). Available online at: http://www.who.int/trypanosomiasis_african/ news/progress-on-eliminating-hat-aspublic-health-problem/en/

5. Shaw AP, Cecchi G, Wint GR, Mattioli RC, Robinson TP. Mapping the economic benefits to livestock keepers from intervening against 
bovine trypanosomosis in Eastern Africa. Prev Vet Med. (2014) 113:197210. doi: 10.1016/j.prevetmed.2013.10.024

6. Baldry DA. A history of Rhodesian sleeping sickness in the Lambwe Valley. Bull World Health Organ. (1972) 47:699-718.

7. Robson J, Ashkar TS. Trypanosomiasis in domestic livestock in the Lambwe Valley area and a field evaluation of various diagnostic techniques. Bull World Health Organ. (1972) 47:727-34.

8. Bourn D, Reid R, Rogers D, Snow B, Wint W. Environmental Change and the Autonomous Control of Tsetse and Trypanosomosis in Sub-Saharan Africa: Case Histories From Ethiopia, The Gambia, Kenya, Nigeria and Zimbabwe. Oxford: Environmental Research Group Oxford (ERGO) (2001).

9. Willett KC. Some observations on the recent epidemiology of sleeping sickness in Nyanza region, Kenya, and its relation to the general epidemiology of Gambian and Rhodesian sleeping sickness in Africa. Trans R Soc Trop Med Hyg. (1965) 59:374-86. doi: 10.1016/0035-9203(65)90055-6

10. Dransfield RD, Brightwell R, Kyorku Ce, Williams B. Control of tsetse fly (Diptera: Glossinidae) populations using traps at Nguruman, south-west Kenya. Bull Entomol Res. (1990) 80:265-76. doi: 10.1017/S000748530005046X

11. Kasozi KI, Zirintunda G, Ssempijja F, Buyinza B, Alzahrani KJ, Matama $\mathrm{K}$, et al. Epidemiology of trypanosomiasis in wildlife-implications for humans at the wildlife interface in Africa. Front Vet Sci. (2021) 8:621699. doi: $10.3389 /$ fvets.2021.621699

12. Diall O, Cecchi G, Wanda G, Argilés-Herrero R, Vreysen MJB, Cattoli G, et al. Developing a progressive control pathway for African Animal Trypanosomosis. Trends Parasitol. (2017) 33:499-509. doi: 10.1016/j.pt.2017.02.005

13. Nesbitt S, Njau B, Otieno L. Epizootiology of trypanosomiasis in Lambwe Valley, Kenya, East Africa. Insect Sci Appl. (1991) 12:37984. doi: $10.1017 /$ S1742758400011243

14. Murray M, Murray PK, McIntyre WIM. An improved parasitological technique for the diagnosis of African trypanosomiasis. Trans $R$ Soc Trop Med Hyg. (1977) 71:325-6. doi: 10.1016/0035-9203(77)90110-9

15. Cox A, Tosas O, Tilley A, Picozzi CK, Coleman PG, Hide G, et al. Constraints to estimating the prevalence of trypanosome infections in East African Zebu Cattle. Parasit Vectors. (2010) 3:82. doi: 10.1186/1756-3305-3-82

16. Njiru ZK, Constantine CC, Guya S, Crowther J, Kiragu JM, Thompson RCA, et al. The use of ITS1 rDNA PCR in detecting pathogenic African trypanosomes. Parasit Res. (2005) 95:186-92. doi: 10.1007/s00436-004-1267-5

17. Hamilton PB, Stevens JR, Gaunt MW, Gidley J, Gibson WC. Trypanosomes are monophyletic: evidence from genes for glyceraldehyde phosphate dehydrogenase and small subunit ribosomal RNA. Int J Parasit. (2004) 34:1393-404. doi: 10.1016/j.ijpara.2004.08.011

18. Hamilton PB, Adams ER, Malele II, Gibson WC. A novel high throughput technique for species identification reveals a new species of tsetse-transmitted trypanosome related to Trypanosoma brucei. Infect Genet Evol. (2008) 8:2633. doi: 10.1016/j.meegid.2007.09.003

19. Constable P, Hinchcliff KW, Done S, Gruenberg W. Veterinary Medicine: A Textbook of the Diseases of Cattle, Horses, Sheep, Pigs and Goats. 11 ed: Saunders Ltd. (2016).

20. Okal MN, Odhiambo BK, Otieno P, Bargul JL, Masiga D, Villinger J, et al. Anaplasma and theileria pathogens in cattle of Lambwe Valley, Kenya: a case for pro-active surveillance in the wildlife-livestock interface. Microorganisms. (2020) 8:1830. doi: 10.3390/microorganisms 8111830

21. Reed GH, Kent JO, Wittwer CT. High-resolution DNA melting analysis for simple and efficient molecular diagnostics. Pharmacogenomics. (2007) 8:597-608. doi: 10.2217/14622416.8.6.597

22. Otieno DO, K’Otuto GO, Jákli B, Schröttle P, Maina JN, Jung E, et al. Spatial heterogeneity in ecosystem structure and productivity in a moist Kenyan savanna. Plant Ecol. (2011) 212:769-83. doi: 10.1007/s11258-010-9863-1

23. Bennett $\mathrm{S}$, Woods $\mathrm{T}$, Liyanage WM, Smith DL. A simplified general method for cluster-sample surveys of health in developing countries. World Health Stat Q. (1991) 44:98-106.

24. Dohoo I, Martin W, Stryhn H. Veterinary Epidemiologic Research: Charlotte. P.E.I.: VER, Inc. (2009).

25. Thrusfield M. Veterinary Epidemiology. John Wiley \& Sons (2018).

26. Otte MJ, Gumm ID. Intra-cluster correlation coefficients of 20 infections calculated from the results of cluster-sample surveys. Prev Vet Med. (1997) 31:147-50. doi: 10.1016/S0167-5877(96)01108-7
27. Simwango M, Ngonyoka A, Nnko HJ, Salekwa LP, Ole-Neselle M, Kimera SI, et al. Molecular prevalence of trypanosome infections in cattle and tsetse flies in the Maasai Steppe, northern Tanzania. Parasit Vectors. (2017) 10:507. doi: 10.1186/s13071-017-2411-2

28. Wittwer CT. High-resolution DNA melting analysis: advancements and limitations. Hum Mutat. (2009) 30:857-9. doi: 10.1002/humu.20951

29. Moser DR, Cook GA, Ochs DE, Bailey CP, McKane MR, Donelson JE. Detection of Trypanosoma congolense and Trypanosoma brucei subspecies by DNA amplification using the polymerase chain reaction. Parasitology. (1989) 99:57-66. doi: 10.1017/S0031182000061023

30. Gibson W, Backhouse T, Griffiths A. The human serum resistance associated gene is ubiquitous and conserved in Trypanosoma brucei rhodesiense throughout East Africa. Infect Genet Evol. (2002) 1:20714. doi: 10.1016/S1567-1348(02)00028-X

31. Welburn SC, Picozzi K, Fevre EM, Coleman PG, Odiit M, Carrington M, et al. Identification of human-infective trypanosomes in animal reservoir of sleeping sickness in Uganda by means of serum-resistance-associated (SRA) gene. Lancet. (2001) 358:2017-9. doi: 10.1016/S0140-6736(01)07096-9

32. Altman DG. Practical Statistics for Medical Research. London; New York, NY: Chapman and Hall (1991).

33. Mbahin N, Affognon H, Andoke J, Tiberius M, Mbuvi D, Otieno J, et al. Parasitological prevalence of bovine trypanosomosis in Kubo division of Kwale county of coastal: baseline survey. Am J Anim Vet Sci. (2013) 8:2836. doi: 10.3844/ajavsp.2013.28.36

34. Ohaga SO, Kokwaro ED, Ndiege IO, Hassanali A, Saini RK. Livestock farmers' perception and epidemiology of bovine trypanosomosis in Kwale District, Kenya. Prev Vet Med. (2007) 80:24-33. doi: 10.1016/j.prevetmed.2007. 01.007

35. Takeet MI, Fagbemi BO, De Donato M, Yakubu A, Rodulfo HE, Peters SO, et al. Molecular survey of pathogenic trypanosomes in naturally infected Nigerian cattle. Res Vet Sci. (2013) 94:555-61. doi: 10.1016/j.rvsc.2012.10.018

36. Leta S, Alemayehu G, Seyoum Z, Bezie M. Prevalence of bovine trypanosomosis in Ethiopia: a meta-analysis. Parasit Vectors. (2016) 9:139. doi: 10.1186/s13071-016-1404-x

37. Abebe R, Gute S, Simon I. Bovine trypanosomosis and vector density in Omo-Ghibe tsetse belt, South Ethiopia. Acta Trop. (2017) 167:7985. doi: 10.1016/j.actatropica.2016.12.016

38. Hamill LC, Kaare MT, Welburn SC, Picozzi K. Domestic pigs as potential reservoirs of human and animal trypanosomiasis in Northern Tanzania. Parasit Vect. (2013) 6:322. doi: 10.1186/1756-3305-6-322

39. Ruiz JP, Nyingilili HS, Mbata GH, Malele II. The role of domestic animals in the epidemiology of human african trypanosomiasis in Ngorongoro conservation area, Tanzania. Parasit Vect. (2015) 8:510. doi: $10.1186 / \mathrm{s} 13071-015-1125-6$

40. Squarre D, Hayashida K, Gaithuma A, Chambaro H, Kawai N, Moonga L, et al. Diversity of trypanosomes in wildlife of the Kafue ecosystem, Zambia. Int J Parasitol Parasites Wildl. (2020) 12:34-41. doi: 10.1016/j.ijppaw.2020. 04.005

41. Odulaja A, Baumgärtner J, Mihok S, Abu-Zinid IM. Spatial and temporal distribution of tsetse fly trap catches at Nguruman, southwest Kenya. Bull Entomol Res. (2001) 91:213-20. doi: 10.1079/BER200084

42. Muriuki GW, Njoka TJ, Reid RS, Nyariki DM. Tsetse control and land-use change in Lambwe valley, south-western Kenya. Agric Ecosyst Environ. (2005) 106:99-107. doi: 10.1016/j.agee.2004.04.005

43. Hargrove JW. A theoretical study of the invasion of cleared areas by tsetse flies (Diptera: Glossinidae). Bull Entomol Res. (2000) 90:2019. doi: $10.1017 /$ S0007485300000328

44. de Clare Bronsvoort BM, von Wissmann B, Fèvre EM, Handel IG, Picozzi K, Welburn SC. No gold standard estimation of the sensitivity and specificity of two molecular diagnostic protocols for Trypanosoma brucei spp. in Western Kenya. PLoS ONE. (2010) 5:e8628. doi: 10.1371/journal.pone.0008628

45. Clausen PH, Wiemann A, Patzelt R, Kakaire D, Poetzsch C, Peregrine A, et al. Use of a PCR assay for the specific and sensitive detection of Trypanosoma Spp. in naturally infected dairy cattle in Peri-urban Kampala, Uganda. Ann N Y Acad Sci. (1998) 849:21-31. doi: 10.1111/j.1749-6632.1998.tb1 1029. $\mathrm{x}$

46. Solano P, Michel J-F, Lefrançois T, de La Rocque S, Sidibe I, Zoungrana A, et al. Polymerase chain reaction as a diagnosis tool for detecting trypanosomes 
in naturally infected cattle in Burkina Faso. Vet Parasitol. (1999) 86:95103. doi: 10.1016/S0304-4017(99)00137-5

47. von Wissmann B, Machila N, Picozzi K, Fèvre EM, deC Bronsvoort BM, Handel IG, et al. Factors associated with acquisition of human infective and animal infective trypanosome infections in domestic livestock in western Kenya. PLoS Negl Trop Dis. (2011) 5:e941. doi: 10.1371/journal.pntd.0 000941

48. Paguem A, Abanda B, Ndjonka D, Weber JS, Ngomtcho SCH, Manchang KT, et al. Widespread co-endemicity of Trypanosoma species infecting cattle in the Sudano-Sahelian and Guinea Savannah zones of Cameroon. BMC Vet Res. (2019) 15:344. doi: 10.1186/s12917-0192111-6

49. Mamoudou A, Njanloga A, Hayatou A, Suh PF, Achukwi MD. Animal trypanosomosis in clinically healthy cattle of north Cameroon: epidemiological implications. Parasit Vectors. (2016) 9:206. doi: 10.1186/s13071-016-1498-1

50. Ngomtcho SCH, Weber JS, Ngo Bum E, Gbem TT, Kelm S, Achukwi MD. Molecular screening of tsetse flies and cattle reveal different Trypanosoma species including $\mathrm{T}$. grayi and $\mathrm{T}$. theileri in northern Cameroon. Parasit Vectors. (2017) 10:631. doi: 10.1186/s13071-0172540-7
Author Disclaimer: The views expressed in this publication are those of the authors and not necessarily those of any of the funding agencies.

Conflict of Interest: The authors declare that the research was conducted in the absence of any commercial or financial relationships that could be construed as a potential conflict of interest.

Publisher's Note: All claims expressed in this article are solely those of the authors and do not necessarily represent those of their affiliated organizations, or those of the publisher, the editors and the reviewers. Any product that may be evaluated in this article, or claim that may be made by its manufacturer, is not guaranteed or endorsed by the publisher.

Copyright (c) 2021 Kalayou, Okal, Odhiambo, Mathenge, Gamba, Kariuki, McOdimba and Masiga. This is an open-access article distributed under the terms of the Creative Commons Attribution License (CC BY). The use, distribution or reproduction in other forums is permitted, provided the original author(s) and the copyright owner(s) are credited and that the original publication in this journal is cited, in accordance with accepted academic practice. No use, distribution or reproduction is permitted which does not comply with these terms. 